\title{
BRAF mutations and phosphorylation status of mitogen-activated protein kinases in the development of flat and depressed-type colorectal neoplasias
}

\author{
K Konishi",', M Takimoto' ${ }^{2}$ K Kaneko', R Makino ${ }^{3}$, Y Hirayama ${ }^{2}$, H Nozawa', T Kurahashi', Y Kumekawa', \\ T Yamamoto', H Ito', N Yoshikawa ${ }^{1,4}$, M Kusano ${ }^{5}, K_{\text {Nakayama }}^{6}$, BJ Rembacken ${ }^{7}$, H Ota $^{2}$ and M Imawari \\ 'Second Department of Internal Medicine, Showa University School of Medicine, I-5-8 Hatanodai, Shinagawa-ku, Tokyo I42-8666, Japan; ${ }^{2}$ Second \\ Department of Pathology, Showa University School of Medicine, Tokyo, Japan; ${ }^{3}$ Clinical Research Laboratory, Showa University School of Medicine, Tokyo, \\ Japan; ${ }^{4}$ Endoscopy center, Showa University Hospital, Tokyo, Japan; ${ }^{5}$ Second Department of Surgery, Showa University School of Medicine, Tokyo, Japan; \\ ${ }^{6}$ Department of Obstetrics and Gynecology, Shimane Medical University, Izumo, Japan; ${ }^{7}$ Centre for Digestive Disease, The General Infirmary, Leeds, UK
}

\begin{abstract}
Although some molecular differences between flat-depressed neoplasias (FDNs) and protruding neoplasias (PNs) have been reported, it is uncertain if the BRAF mutations or the status of phosphorylated mitogen-activated protein kinase ( $P$-MAPK) are different between theses two groups. We evaluated the incidence of BRAF and KRAS mutations, high-frequency microsatellite instability $(\mathrm{MSI}-\mathrm{H})$, and the immunohistochemical status of P-MAPK in the nonserrated neoplasias (46 FDNs and 57 PNs). BRAF mutations were detected in four FDNs $(9 \%)$ and none of PNs $(P=0.0369$ by Fisher's exact test). KRAS mutations were observed in none of FDNs and in I 4 PNs (25\%; $P=0.0002$ by Fisher's exact test). MSI-H was detected in seven out of 44 FDNs (I 6\%) and in one out of 52 of PNs (2\%) ( $P=0.022$ by Fisher's exact test). Type $B$ and $C$ immunostaining for $p-M A P K$ was observed in 34 out of 46 FDNs (72\%), compared with 24 out of 55 PNs (44\%; $P=0.0022$ by $\chi^{2}$ test). There was no significant difference in the type B and $C$ immunostaining of $\mathrm{P}-\mathrm{MAPK}$ between FDNs with and without BRAF mutations. BRAF and KRAS mutations are mutually exclusive in the morphological characteristics of colorectal nonserrated neoplasia. Abnormal accumulation of p-MAPK protein is more likely to be implicated in the tumorigenesis of FDNs than of PNs. However, this abnormality in FDNs might occur via the genetic alteration other than BRAF or KRAS mutation.
\end{abstract}

British Journal of Cancer (2006) 94, 31 I-317. doi:I0.1038/sj.bjc.66029II www.bjcancer.com

Published online 13 December 2005

(c) 2006 Cancer Research UK

Keywords: depressed neoplasia; flat adenomaBRAF mutation; colorectal carcinoma; MAPK pathways; colorectal polyp

The adenoma-carcinoma sequence is well accepted as a major pathway for the development of colorectal cancers (CRCs) (Morson, 1968). Most CRCs are thus believed to arise from preexisting adenomatous polyps. Most of these benign precursor lesions are of polypoid, protruding origin (Muto et al, 1975); however, many investigators have reported flat and depressed neoplasias (FDNs) as a new type of precursors of CRC and propose that these tumours develop through a de novo pathway, as they are not associated with adenoma components (Bedenne et al, 1992; Iishi et al, 1992; Kudo, 1993; Minamoto et al, 1994b; Konishi et al, 1999; Rembacken et al, 2000; Saitoh et al, 2001). Flat-depressed neoplasias are characterised by a higher potential of malignancy than protruding neoplasias (PNs) (Kudo, 1993). Small nonpolypoid cancers have particularly greater aggressiveness than polypoid cancers of equivalent size (Minamoto et al, 1994b).

Genetic alterations in the adenoma-carcinoma sequence comprise two groups (Kinzler and Vogelstein, 1996). The major group is

*Correspondence: Dr K Konishi; E-mail: konishigi@hotmail.com Received 27 June 2005; revised 7 November 2005; accepted 21 November 2005; published online 13 December 2005 characterised by a mechanism associated with loss of heterozygosity $(\mathrm{LOH})$, which accounts for a significant proportion of tumour suppressor gene (adenomatous polyposis coli (APC) or p53) inactivation (Baker et al, 1989; Powell et al, 1992). Additionally, mutational activation of KRAS has been found in about $40 \%$ of colorectal neoplasias (Bos et al, 1987; Forrester et al, 1987). This group accounts for at least two thirds of all CRCs. Another group of cancers exhibits a high frequency of DNA microsatellite instability (MSI) caused by inactivation of DNA mismatch repair (MMR) genes such as hMLH1 (Bronner et al, 1994). Inactivation of this gene, which resulted from bialleleic hypermethylation of the promoter, leads to destabilisation of simple DNA repeat sequence in colorectal tumours (Cunningham et al, 1998; Herman et al, 1998). Tumour suppressor gene inactivation occurs as a consequence of the state of microsatellite instability.

Some molecular differences between FDNs and PNs have been reported. Mutational activation of KRAS is a rare event in FDNs, compared with PNs (Fujimori et al, 1994; Minamoto et al, 1994a; Yamagata et al, 1994; Yashiro et al, 2001). There are also distinct differences in chromosomal changes between FDNs and PNs (Richter et al, 2003). However, no significant difference in incidence has been observed for somatic mutations in APC and 
p53 (Olschwang et al, 1998; van Wyk et al, 2000). Thus, molecular analysis of FDNs is important for achieving a better understanding of the mechanism in the development of CRCs.

The Ras/Raf/MEK/mitogen-activated protein kinase (MAPK) (MEK is the MAPK or extracellular signal-related kinase (ERK) kinase) cascade mediates cellular response to growth signals (Peyssonnaux and Eychene, 2001). Somatic mutations of the Ras gene, leading to activation of this signalling pathway and malignant transformation, are frequently observed in protruding tumours (Fujimori et al, 1994; Minamoto et al, 1994a; Yamagata et al, 1994; Yashiro et al, 2001; Chan et al, 2003). Davies et al (2002) have reported the presence of $B R A F$ mutations in human cancers such as melanomas, colorectal, and ovarian cancers. BRAF mutations in these cancers are oncogenic. BRAF proteins, Ras-regulated kinase, phosphorylate MEK1 and MEK2, which in turn phosphorylate MAPK-ERK 1/2. The activated version of $B R A F$, at least in part, promotes cell proliferation by signalling through MEK and ERK (Davies et al, 2002). Moreover, BRAF mutations occur in a mutually exclusive relationship with KRAS mutations, and are closely related to the carcinogenesis of sporadic CRCs with high-frequency MSI (MSI-H) (Rajagopalan et al, 2002; Wang et al, 2003).

Recently, molecular characteristics of serrated adenomas (SAs) are reported to be different from those of nonserrated neoplasia. $B R A F$ mutations are frequently observed in SAs or hyperplastic polyps (Chan et al, 2003; Kambara et al, 2004; Konishi et al, 2004). However, it remains unknown whether $B R A F$ mutations or the status of phosphorylated MAPK (p-MAPK) are the contributors to the tumorigenesis of FDNs, a new type of precursors of CRC. Thus, we evaluated these statuses between flat-depressed and protruding nonserrated neoplasia.

The aim of this study was to investigate the incidence of $B R A F$ mutations in a sizable number of FDNs and its implication for KRAS mutations, for MSI, and for the immunohistochemical status of p-MAPK, and to compare these genetic and immunohistochemical characteristics of FDNs with PNs as controls.

\section{MATERIALS AND METHODS}

\section{Subjects}

A total of 46 FDNs from 44 patients who underwent endoscopic $(N=33)$ or surgical resection $(N=13)$ at Showa University Hospital between April 1998 and January 2004 were used for this study. A series of 57 endoscopically or surgically resected PNs were used as controls. We excluded patients who had familial adenomatous polyposis, hereditary nonpolyposis colorectal cancers, or hyperplastic polyposis, and patients with sporadic SAs. Specimen collection procedures and genetic analysis were approved by the ethical committee of Showa University School of Medicine.

\section{Macroscopic criteria}

Macroscopically, each neoplastic lesion was classified as an FDN or a PN, according to the modified criteria described previously (Konishi et al, 2003). Briefly, FDNs were defined as slightly mucosal elevations with a flat or slightly rounded surface and a height of less than half of the diameter of the lesions, usually consisting of dysplastic mucosal thickness less than twice that of the adjacent nondysplastic mucosa by histology. Flat-depressed neoplasias were subclassified into flat or depressed neoplasias, depending on whether a depressed component was present. Protruding neoplasias were defined as protruding lesions with or without stalks (sessile, semipedunclated, or pedunculated lesions).

\section{Histological evaluation}

Serial sections ( $3 \mu \mathrm{m})$ were cut from paraffin blocks, and prepared for hematoxylin-eosin (HE) staining and immunostaining. All
HE-stained sections were reviewed by a single pathologist (YH), who was blinded to the colonoscopic findings. Dysplastic mucosal lesions were classified as adenomas. When tumour cells had spread through the muscularis mucosa into the submucosa, the lesion was defined as a carcinoma. According to the criteria described previously (Konishi et al, 1999), tumour location was classified into three groups: rectum, left-colon (left-c), and right-colon (right-c). Other histopathological features were determined according to the general rules of the Japanese Research Society for Cancer of the Colon and Rectum (Japanese Research Society for Cancer of the Colon and Rectum, 1997).

\section{DNA preparation}

To extract genomic DNA, five adjacent sections (5- $\mu \mathrm{m}$ thick) were obtained from an archival block of formalin-fixed, paraffinembedded tumour tissue for each macroscopic type. One section was stained with $\mathrm{HE}$, and the percentage of tumour cells was estimated microscopically. The extraction of genomic DNA was described previously (Yamamoto et al, 2003). If representative tumour samples contained less than $80 \%$ tumour cells, separate samples were obtained from the histological slide for tumourous or adjacent normal tissue using laser-capture microdissection, as described previously (Yamamoto et al, 2003). DNA samples from normal colonic mucosa (frozen or formalin-fixed tissue) or peripheral blood were used as normal controls for molecular analysis.

\section{Mutations in BRAF and KRAS}

Primers for exons 11 and 15 were used to evaluate BRAF mutations (Davies et al, 2002; Chan et al, 2003). These primers included the region of mutation 'hot spots' previously identified in this gene. PCR amplification of exon of a KRAS-containing codon 12 or 13 was performed using previously described primers (Brose et al, 2002). Mutational screening of the BRAF and KRAS genes was performed by direct sequencing methods, as previously reported (Makino et al, 2000). The PCR products were separated by electrophoresis on $2 \%$ agarose gels and eluted with GenElute ${ }^{\mathrm{TM}}$ Minus EtBr Spin Columns (Sigma, Saint Louis, MO, USA). The purified sample was sequenced using an automated sequencer. All mutations were reconfirmed by independent PCR reactions and sequencing.

\section{Analysis of MSI}

PCR was performed to amplify DNA samples from the tumours and the adjacent normal tissues using an established PCR protocol (Konishi et al, 2004). Five microsatellite loci analysed in this study were BAT25, BAT26, D2S123, D5S346, and D17S250 (Boland et al, 1998). Tumours showing novel peak patterns were evaluated as MSI positive. A single observer (HN) performed the MSI analysis, and positive or equivocal samples were re-evaluated by a second observer $(\mathrm{KN})$. A tumour sample was considered to contain highfrequency MSI (MSI-H) if two or more of the five informative markers demonstrated instability, and was considered to have low-frequency MSI (MSI-L) when only one marker was unstable (Boland et al, 1998). All PCR reactions were repeated on the same sample and only consistent changes in the duplicate reactions were scored as abnormalities.

\section{Immunohistochemical staining and evaluation of p-MAPK}

Deparaffinised and rehydrated sections were heated in a microwave oven in sodium citrate buffer ( $\mathrm{pH} \mathrm{6.0)}$ for 30 min to retrieve antigens. Endogenous peroxidase activity was inhibited by incubation with $3 \%$ hydrogen peroxide for $5 \mathrm{~min}$. Sections were incubated overnight with polyclonal anti-phospho-p44/42 MAPK 
antibody (Anti-ACTIVE MAPK pAb; Promega, Madison, WI, USA) at $4{ }^{\circ} \mathrm{C}$. This specifically recognises the dually phosphorylated, active form of MAPK (p44/ERK1 and p42/ERK2). The working dilution was $1: 300$. Sections were then incubated with horseradish peroxidase-binding amino-acid polymer for $30 \mathrm{~min}$ (Histofine Simplestain MAX-PO kit, Nichirei, Tokyo, Japan). Colour was developed by staining with a diaminobenzidine solution. Sections were lightly counterstained with haematoxylin.

Each immunostained section was examined under a light microscope and evaluated for the nuclear staining (Figure 1A) twice by a senior pathologist (MT) who did not have any knowledge of the clinical and molecular analysis of those samples. At the present, there are no validated criteria for evaluating immunohistochemical staining for p-MAPK; therefore, we used a grading system for evaluating p-MAPK staining based on staining distribution. The dysplastic or normal mucosa glands were divided into three equal areas (upper, middle, and lower). P-MAPKpositive cells were classified into three types (Figure 1): type A, localised within the upper area only; type $\mathrm{B}$, localised in the upper and middle; type $\mathrm{C}$, localised in the upper through lower. We analysed the immunostaining of p-MAPK separately in tumour and adjacent normal tissue. Unfortunately, two paired PNs and adjacent normal mucosa, and five samples of adjacent normal mucosa were not informative for p-MAPK immunostaining, because of the small amounts of tissue in the blocks.

\section{Statistical analysis}

Mann-Whitney $U$-test, $\chi^{2}$ test, and Fisher's exact test were used for statistical analysis. A value of $P<0.05$ was considered significant.

\section{RESULTS}

There were no significant differences in gender, age, family history of CRC, location, size, or histology between the two macroscopic types. The incidence of accompanying adenoma in the Duke's type A carcinomas was lower in the FDNs than in the PNs (four out of 17 and 12 out of 13 , respectively; $P=0.0002$ by Fisher's exact test) (Table 1).

$B R A F$ mutations were detected in four out of 46 of FDNs (9\%) and none of the 57 PNs. This difference was statistically significant $(P=0.0369$ by Fisher's exact test). Three BRAF mutations were found in exon 15 and two were in exon 11 (Table 2). One tumour had BRAF mutations in both exons. Two exon 15 mutations observed in depressed neoplasias were the conversion of valine to glutamic acid at codon 599. The remaining findings were novel mutations, P452T (exon 11) in two tumours and T588I (exon 15) in one tumour. Of the four FDNs with BRAF mutations, no BRAF mutation was detected in the adjacent normal mucosa.

KRAS mutations were observed in none of 46 FDNs and 14 out of 57 of PNs $(25 \%)$. There was significant difference in the incidence of KRAS mutations between FDNs and PNs $(P=0.0002$ by Fisher's exact test). All but one KRAS mutation was detected in codon 12 of the KRAS gene (Table 2).

For the MSI analysis, MSI-H was shown in seven out of 44 FDNs $(16 \%)$ and in one out of 52 PNs $(2 \%)$. This incidence of MSI-H differed significantly between FDNs and PNs $(P=0.022$ by Fisher's exact test). MSI-L was shown in 16 out of 44 FDNs (36\%) and in six out of 52 PNs (12\%: $P=0.0066$ by Fisher's exact test). Of the seven FDNs with MSI-H, four were adenomas and three were Duke's type A carcinomas, whereas one PN with MSI-H were adenomas. BRAF mutations were found in one out of seven FDNs with MSI-H (14\%) and in three out of 37 FDNs without MSI-H (8\%). However, these differences were not statistically significant. No KRAS mutation was observed in any PN with MSI-H.
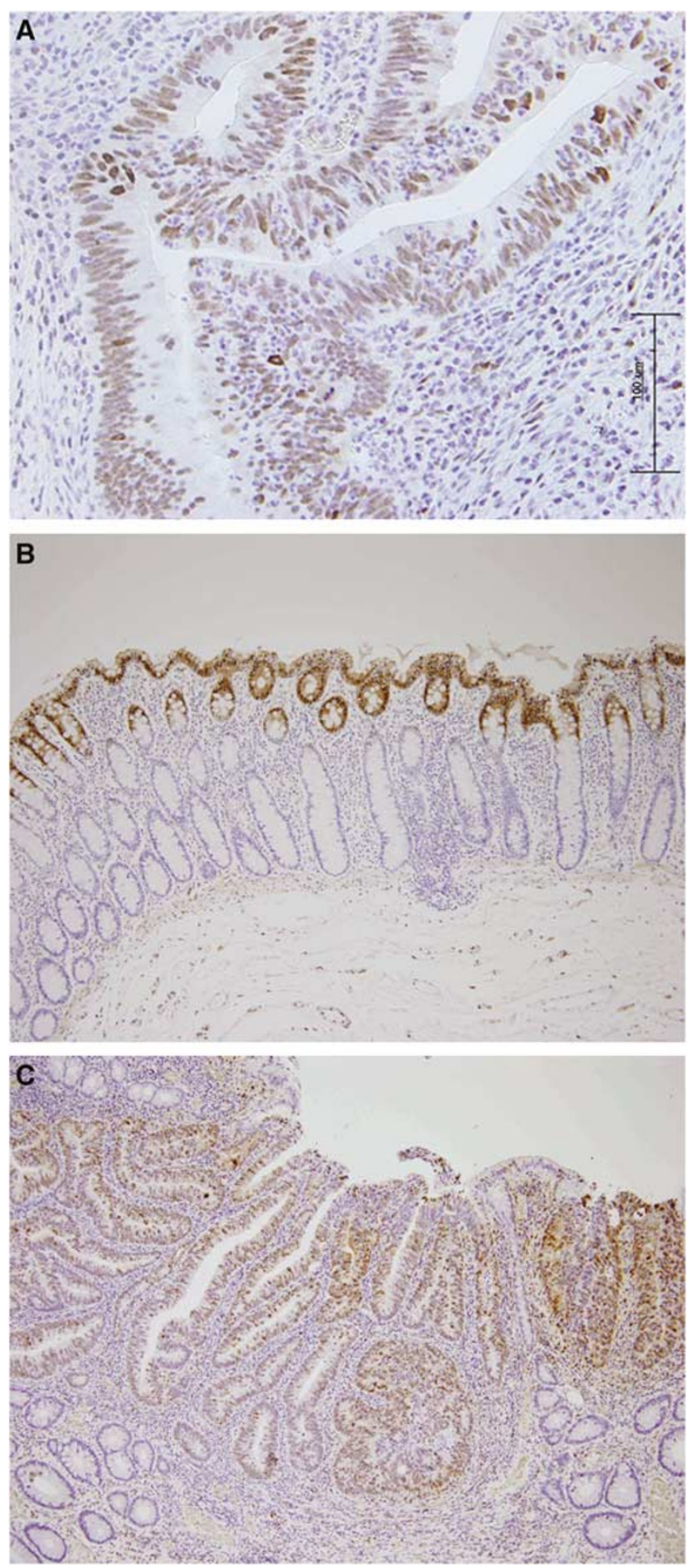

Figure I Immunohistochemical staining of phosphorylated mitogenactivated protein kinase (P-MAPK). (A) Nuclear expression in a colonic neoplasia. (B) In type A, p-MAPK-positive cells were localised within the upper area of the adjacent normal mucosa $(\times 10)$. (C) In type C, p-MAPKpositive cells were localised in the upper, middle through lower area of the tumour $(\times 10)$

The p-MAPK protein was detected immunohistochemically in all samples to a variable extent. Type B and $\mathrm{C}$ immunostaining for p-MAPK was observed in 34 out of 46 FDNs (72\%), compared with 24 out of 55 PNs (44\%). This difference was statistically significant 
( $P=0.0022$ by $\chi^{2}$ test $)$. However, about $80 \%$ of the adjacent normal mucosa showed type A p-MAPK expression. There was no significant difference in the incidence of type A p-MAPK

Table I Clinicopathological characteristics of patients with flat and depressed neoplasias, and protruding neoplasia

\begin{tabular}{|c|c|c|c|}
\hline & FDNs $(N=46)$ & PNs $(N=57)$ & $P$-value \\
\hline \multicolumn{4}{|l|}{ Gender } \\
\hline Male/female & $34 / 10$ & $34 / 16$ & $0.3159 *$ \\
\hline $\begin{array}{l}\text { Mean age (year) } \\
\text { (Range) }\end{array}$ & $\begin{array}{c}66.1 \\
(4 I-85)\end{array}$ & $\begin{array}{c}65.4 \\
(32-82)\end{array}$ & $0.700 \mid * *$ \\
\hline \multicolumn{4}{|l|}{ Family history of $C R C$} \\
\hline Present & 4 & 3 & $0.3158 *$ \\
\hline Absent & 35 & 45 & \\
\hline Unknown & 5 & 2 & \\
\hline \multicolumn{4}{|l|}{ Location } \\
\hline Left-c and rectum & 17 & 26 & $0.3575 *$ \\
\hline Right-c & 29 & 31 & \\
\hline \multicolumn{4}{|l|}{ Size } \\
\hline$<10 \mathrm{~mm}$ & 14 & 23 & $0.2970 *$ \\
\hline$\geqslant 10 \mathrm{~mm}$ & 32 & 34 & \\
\hline \multicolumn{4}{|l|}{ Macroscopic type } \\
\hline Flat & 27 & NA & \\
\hline Depressed & 19 & & \\
\hline \multicolumn{4}{|l|}{ Histology } \\
\hline Adenoma & 29 & 44 & $0.1161 *$ \\
\hline Dukes' A carcinoma & 17 & 13 & \\
\hline \multicolumn{4}{|c|}{ Accompanying adenoma in Dukes' A carcinoma } \\
\hline Present & 4 & 12 & $0.0002 * * * *$ \\
\hline Absent & 13 & I & \\
\hline
\end{tabular}

FDNs = flat and depressed neoplasias; PNs = protruding neoplasias; $C R C=$ colorectal cancers; $N A=$ not applicable. $* P$-value calculated by $\chi^{2}$ test; $* * P$-value calculated by Mann-Whitney U-test; **** $P$-value calculated by Fisher's exact test. expression in the adjacent normal mucosa between FDNs and PNs (34 out of 46 and 42 out of 50, respectively; $P=0.2241$ by $\chi^{2}$ test).

We compared the clinicopathological and molecular characteristics between neoplasia with type $A$ and with type $B / C$ immunostaining of p-MAPK (Table 3). In the FDNs, type $B / C$ expression of p-MAPK was observed significantly more frequently in Duke's A carcinomas than in the adenomas $(P=0.0338$ by Fisher's exact test). We observed no significant difference in the incidence of type B/C immunostaining of p-MAPK between FDNs with and without $B R A F$ mutations. In contrast, type $B / C$ immunostaining for p-MAPK was detected more frequently in large $(\geqslant 10 \mathrm{~mm})$ than small $(<10 \mathrm{~mm})$ PNs. This size-related difference was statistically significant $(P=0.0265$ by Fisher's exact test). Type B/C immunostaining of p-MAPK was demonstrated more frequently in PNs with KRAS mutations than without KRAS mutations $(P=0.0272$ by Fisher's exact test).

\section{DISCUSSION}

$B R A F$ status has been examined in a variety of human malignancies. BRAF mutations have been reported in approximately $10 \%$ of CRCs (Davies et al, 2002; Rajagopalan et al, 2002; Fransen et al, 2004). However, the status of the BRAF gene in the precursor lesions of CRCs has not been thoroughly explored, and there is morphological heterogeneity in the oncogenesis (Shimoda et al, 1989). Flat-depressed and protruding adenomas may be the precursors to cancers arising de novo and to polypoid cancers, respectively. To our knowledge, this is the first study of the mutational status of $B R A F$ in terms of the morphological characteristics of colorectal nonserrated neoplasias. Protruding neoplasias have a significantly higher frequency of KRAS mutation than flat neoplasias, despite the similarity of the tumour size (Fujimori et al, 1994; Minamoto et al, 1994a; Yamagata et al, 1994; Yashiro et al, 2001). We identified four FDNs (9\%) with mutations in BRAF, but no PNs with the mutations. By contrast, KRAS mutations were observed in none of FDNs and in 25\% of PNs. $B R A F$ and KRAS mutations were mutually exclusive in the

Table 2 Characteristics of colorectal neoplasias with BRAF or KRAS mutations

\begin{tabular}{|c|c|c|c|c|c|c|c|c|}
\hline Sample & Location & Size $(\mathrm{mm})$ & Histology & \multicolumn{2}{|c|}{ Sequence change } & Codon & Amino-acid substitution & p-MAPK ${ }^{a}$ \\
\hline \multicolumn{9}{|c|}{ BRAF mutations } \\
\hline $\mathrm{DN}$ & $A$ & 25 & Dukes' A & 1796 & $\mathrm{~T} \rightarrow \mathrm{A}$ & 599 & $V \rightarrow E$ & B \\
\hline FN & $\mathrm{D}$ & 10 & Adenoma & 1354 & $C \rightarrow A$ & 452 & $\mathrm{P} \rightarrow \mathrm{T}$ & $A$ \\
\hline FN & $\mathrm{T}$ & || & Adenoma & 1763 & $\mathrm{C} \rightarrow \mathrm{T}$ & 588 & $\mathrm{~T} \rightarrow \mathrm{I}$ & C \\
\hline \multirow[t]{2}{*}{ DN } & $\mathrm{T}$ & 8 & Adenoma & 1354 & $C \rightarrow A$ & 452 & $\mathrm{P} \rightarrow \mathrm{T}$ & A \\
\hline & & & & 1796 & $\mathrm{~T} \rightarrow \mathrm{A}$ & 599 & $V \rightarrow E$ & \\
\hline \multicolumn{9}{|c|}{ KRAS mutations } \\
\hline PN & $A$ & 12 & Adenoma & 35 & $\mathrm{G} \rightarrow \mathrm{T}$ & 12 & $G \rightarrow V$ & $B$ \\
\hline PN & $A$ & 3 & Adenoma & 35 & $G \rightarrow C$ & 12 & $\mathrm{G} \rightarrow \mathrm{A}$ & $A$ \\
\hline PN & $\mathrm{D}$ & 9 & Adenoma & 35 & $\mathrm{G} \rightarrow \mathrm{A}$ & 12 & $G \rightarrow D$ & B \\
\hline PN & $\mathrm{S}$ & 8 & Adenoma & 35 & $G \rightarrow C$ & 12 & $\mathrm{G} \rightarrow \mathrm{A}$ & C \\
\hline PN & $A$ & 32 & Adenoma & 35 & $\mathrm{G} \rightarrow \mathrm{T}$ & 12 & $\mathrm{G} \rightarrow \mathrm{V}$ & B \\
\hline PN & $S$ & 35 & Adenoma & 35 & $\mathrm{G} \rightarrow \mathrm{A}$ & 12 & $G \rightarrow D$ & $A$ \\
\hline PN & $A$ & 50 & Adenoma & 35 & $\mathrm{G} \rightarrow \mathrm{T}$ & 12 & $\mathrm{G} \rightarrow \mathrm{V}$ & B \\
\hline PN & C & 40 & Dukes' A & 34 & $\mathrm{G} \rightarrow \mathrm{T}$ & 12 & $\mathrm{G} \rightarrow \mathrm{C}$ & $A$ \\
\hline PN & $\mathrm{R}$ & 30 & Dukes' A & 35 & $G \rightarrow A$ & 12 & $G \rightarrow D$ & B \\
\hline PN & A & 7 & Adenoma & 35 & $\mathrm{G} \rightarrow \mathrm{C}$ & 12 & $\mathrm{G} \rightarrow \mathrm{A}$ & B \\
\hline PN & $\mathrm{T}$ & 40 & Dukes' A & 35 & $\mathrm{G} \rightarrow \mathrm{A}$ & 12 & $G \rightarrow D$ & $A$ \\
\hline PN & $\mathrm{T}$ & 12 & Adenoma & 35 & $G \rightarrow A$ & 12 & $G \rightarrow D$ & B \\
\hline PN & $\mathrm{T}$ & 30 & Adenoma & 35 & $\mathrm{G} \rightarrow \mathrm{A}$ & 12 & $G \rightarrow D$ & B \\
\hline PN & $\mathrm{R}$ & 35 & Adenoma & 38 & $\mathrm{G} \rightarrow \mathrm{A}$ & 13 & $\mathrm{G} \rightarrow \mathrm{D}$ & B \\
\hline
\end{tabular}

${ }^{a}$ Evaluating systems for immunohistochemical staining for $\mathrm{p}-\mathrm{MAPK}$ are described in Materials and Methods. $\mathrm{P}=$ positive immunostaining; $\mathrm{N}=$ negative immunostaining; $\mathrm{FN}=$ flat neoplasia; $\mathrm{DN}=$ depressed neoplasia; $\mathrm{PN}=$ protruding neoplasia; $\mathrm{R}=$ rectum; $\mathrm{S}=$ sigmoid; $\mathrm{D}=\operatorname{descending;} \mathrm{T}=$ transverse; $\mathrm{A}=$ ascending colon; $\mathrm{C}=$ cecum; Dukes' $\mathrm{A}=\mathrm{Dukes}$ A carcinoma; $\mathrm{p}-\mathrm{MAPK}=$ phosporylated mitogen-activated protein kinase. 
Table 3 Expression of phosphorylated MAPK in flat-depressed and protruding neoplasias compared with clinicopathological and molecular characteristics

\begin{tabular}{|c|c|c|c|c|c|c|}
\hline & \multicolumn{6}{|c|}{ Expression of p-MAPK } \\
\hline & \multicolumn{2}{|c|}{ FDNs $(N=46)$} & \multirow[b]{2}{*}{$P$-value } & \multicolumn{2}{|c|}{ PNs $(N=55)$} & \multirow[b]{2}{*}{$P$-value } \\
\hline & $\begin{array}{c}\text { Type } \\
\text { A }\end{array}$ & $\begin{array}{l}\text { Type } \\
\text { B/C }\end{array}$ & & $\begin{array}{c}\text { Type } \\
\text { A }\end{array}$ & $\begin{array}{c}\text { Type } \\
\text { B/C }\end{array}$ & \\
\hline \multicolumn{7}{|l|}{ Location } \\
\hline Left-c and rectum & 3 & 14 & $0.4893 *$ & 13 & 12 & $0.5514 * *$ \\
\hline Right-c & 9 & 20 & & 18 & 12 & \\
\hline \multicolumn{7}{|l|}{ Size } \\
\hline$<10 \mathrm{~mm}$ & 3 & ।1 & $0.7294 *$ & 16 & 5 & $0.0265 *$ \\
\hline$\geqslant 10 \mathrm{~mm}$ & 9 & 23 & & 15 & 19 & \\
\hline \multicolumn{7}{|l|}{ Macroscopic type } \\
\hline Flat & 9 & 18 & $0.307 \mid *$ & NA & & \\
\hline Depressed & 3 & 16 & & & & \\
\hline \multicolumn{7}{|l|}{ Histology } \\
\hline Adenoma & 11 & 18 & 0.0338* & 23 & 19 & $0.7561^{*}$ \\
\hline Dukes' A carcinoma & I & 16 & & 8 & 5 & \\
\hline \multicolumn{7}{|l|}{ BRAF mutation } \\
\hline Mut+ & 2 & 2 & $0.2758 *$ & 0 & 0 & NA \\
\hline Mut- & 10 & 32 & & 31 & 24 & \\
\hline \multicolumn{7}{|l|}{ KRAS mutation } \\
\hline Mut+ & 0 & 0 & NA & 4 & 10 & $0.0272 *$ \\
\hline Mut- & 12 & 34 & & 27 & 14 & \\
\hline \multicolumn{7}{|l|}{$M S I^{\mathrm{a}}$} \\
\hline MSS/MSI-L & I1 & 26 & $0.6532 *$ & 30 & 19 & $>0.999 *$ \\
\hline MSI-H & I & 6 & & I & 0 & \\
\hline
\end{tabular}

Evaluating systems for immunohistochemical staining for p-MAPK are described in Materials and Methods. ${ }^{\text {T}}$ The numbers for MSI reflect the numbers of cases among the informative cases. p-MAPK = phosphorylated mitogen-activated protein kinase; FDNs = flat and depressed neoplasias; PNs = protruding neoplasias; Left- $\mathrm{c}=$ sigmoid and descending colon; Right- $\mathrm{c}=$ transverse, ascending colon, and cecum; Mut+ = presence of mutation; Mut $-=$ absence of mutation; $\mathrm{MSI}=$ microsatellite instability; MSS = microsatellite stable; $M S I-L=$ low-frequency MSI; MSI-H = high-frequency MSI; $\mathrm{NA}=$ not applicable. ${ }^{*} P$-value calculated by Fisher's exact test; ${ }^{*} *$-value calculated by $\chi^{2}$ test.

morphologically distinct nonserrated neoplasias (FDNs and PNs, respectively).

The mutational spots of $B R A F$ gene cluster within the activation segment (exon 15) and the G-loop (exon 11) of the kinase domain, which are highly conserved among serine/threonine kinases throughout evolution. In our series, all of the mutations in exon 15 of $B R A F$ observed in depressed neoplasias (DNs) involved conversion of valine to glutamic acid at codon 599 (V599E). This V599E mutation is a 'hot spot' mutation of colorectal cancers, as well as other human cancers (Davies et al, 2002; Rajagopalan et al, 2002; Wang et al, 2003; Yuen et al, 2003; Domingo et al, 2004; Fransen et al, 2004; Koinuma et al, 2004). Although we need more extensive analysis, V599E mutations might contribute to tumorigenesis in DNs. The other non-V559 mutations detected here were the novel mutations, P452T (exon 11) and T588I (exon 15), in CRCs. This T588I mutation may be associated with increased MAPK activity because the tumour with this mutation showed a type $\mathrm{B}$ and $\mathrm{C}$ expression of p-MAPK protein.

Continuous activation of the MAPK signalling pathway is of critical importance for the development of CRCs. P-MAPK forms (phosphorylated ERK1 and ERK2) translocate to the nucleus to modulate gene expression through the activation of transcriptional factors (Peyssonnaux and Eychene, 2001). Nuclear staining was observed here as a positive reaction for $\mathrm{p}$-MAPK protein, and type $\mathrm{B}$ and $\mathrm{C}$ immunostaining of p-MAPK was frequently observed in the FDNs or PNs. The incidence of type $\mathrm{B}$ and $\mathrm{C}$ immunostaining of p-MAPK was significantly higher in the FDNs than in the PNs. Thus, abnormal accumulation of p-MAPK protein is more likely to be associated with the tumorigenesis of FDNs than of PNs.

Mutational activation of $B R A F$ or KRAS gene signals act through the classical MAPK cascade to promote proliferation (Davies et al, 2002). We found that type $B / C$ expression of p-MAPK was more frequently observed in PNs with a KRAS mutation. Therefore, the mutational type of KRAS might activate the MAPK pathway more strongly than the wild-type KRAS (Vojtek and Der, 1998). Type B/C immunostaining of p-MAPK was observed more frequently in the large PNs than in small PNs. The KRAS gene mutation frequency in colorectal polyps increases in proportion to their size (Vogelstein et al, 1988). Of the 14 PNs with KRAS mutations in this series, 11 (79\%) were adenomas. Thus, derangement of the MAPK signalling pathway may be an early, size-dependent event in the tumorigenesis of PNs, and correlates to the status of KRAS mutation. On the other hands, there was no significant difference in the incidence of type B/C immunostaining of p-MAPK between FDNs with and without $B R A F$ mutations. Type $\mathrm{B} / \mathrm{C}$ immunostaining of $\mathrm{p}-\mathrm{MAPK}$ was more common in Duke's A carcinomas than in adenomas of FDNs. This implies that abnormal accumulation of p-MAPK protein may be a critical event in the tumour progression of FDNs, independently of $B R A F$ mutations.

Our immunohistochemical data suggest that alterations of the MAPK pathway are important for the development of FDNs, but may also highlight new therapeutic strategies for dealing with CRCs that arise from FDNs. As more than 70\% of FDNs show positive immunostaining of $\mathrm{p}-\mathrm{MAPK}$, this signalling pathway may play an important role in the tumorigenesis of FDNs. Many have reported CRCs arising from FDNs or nonpolypoid neoplasias (Shimoda et al, 1989; Bedenne et al, 1992; Iishi et al, 1992; Kudo, 1993; Minamoto et al, 1994b; Konishi et al, 1999; Rembacken et al, 2000; Kaneko et al, 2004). Therefore, inhibition of either p-MAPK or related molecule might be a new therapeutic strategy to treat these CRCs. CI-1040 (PD184352) is highly selective inhibitor of the MAPK signalling cascade specifically targeting the inhibition of MEK (Delaney et al, 2002). Antitumour activity was found to correlate with CI-1040-mediated inhibition of phosphorylated ERK levels. However, $B R A F$ mutations are infrequent in FDNs. Moreover, no significant mutations in ARAF or RAF-1 have been found in CRCs (Fransen et al, 2004). However, the Raf-MEK-ERK pathway is regulated via the interaction with and modulation of the function of a wide range of signalling proteins (English et al, 1999; Zimmermann and Moelling, 1999; Kolch, 2000). Therefore, further investigation is required to clarify what leads to the tumour-specific expression of p-MAPK in FDNs.

We found MSI-H in seven of 44 FDNs (16\%) but in only one of 52 PNs (2\%). Of the seven FDNs with MSI-H, four were adenomas and three were Duke's A carcinomas. Olschwang et al (1998) reported that eight out of 36 flat colorectal neoplasias showed MSI-H (22\%). The frequency of MSI-H in that series did not differ with regard to the histological type. However, Yashiro et al (2001) observed no significant difference in the incidence of MSI-H between flat-type and polypoid-type cancers (four out of 25 and zero out of 25 , respectively). Selection of tumour samples may explain this difference. In our series, $41 \%$ of FDNs showed depressed type morphology and about two-thirds of FDNs were $10 \mathrm{~mm}$ or more in diameter. However, they also suggested that some flat neoplasias may progress to de novo cancers with $\mathrm{LOH}$ at chromosome $3 \mathrm{p}$, the location of $h M L H 1$, and this could explain the onset of MSI-H as an alternative mechanism to hypermethylation of the promoter of $h M L H 1$. Previous studies (Rajagopalan et al, 2002; Wang et al, 2003; Domingo et al, 2004; Koinuma et al, 2004) have reported that $B R A F$ mutations occur more frequently in 
microsatellite-unstable than in microsatellite-stable CRCs. However, we observed no significant difference in the incidence of $B R A F$ mutations between FDNs with and without MSI-H.

In summary, BRAF and KRAS mutations were mutually exclusive in the morphological characteristics of colorectal nonserrated neoplasias. High-frequency microsatellite instability was significantly more frequently seen in FDNs than in PNs. Therefore, it is possible that some FDNs with BRAF mutation or MSI-H progress to de novo type cancers (ie, flat or depressed cancers without accompanying adenoma). Abnormal accumulation of p-MAPK protein seems to be more frequently implicated in the tumorigenesis of FDNs than that of PNs. However, this accumulation was significantly correlated with the incidence of KRAS mutations in PNs, but not to that of BRAF mutations in
FDNs. Derangement of the MAPK pathway in FDNs might occur via the genetic alteration other than $B R A F$ or KRAS mutation.

\section{ACKNOWLEDGEMENTS}

We thank Ms Yoshiko Sasaki (Second Department of Pathology, Showa University School of Medicine) for her excellent technical assistance in this study. This research was supported in part by a Special Research Grant-in-Aid for Development of Characteristic Education from the Japanese Ministry of Education, Culture, Sports, Science and Technology of Japan. This research was also supported in part by a Grant-in-Aid from the Ministry of Health, Labour, and Welfare (14-36).

\section{REFERENCES}

Baker SJ, Fearon ER, Nigro JM, Hamilton SR, Preisinger AC, Jessup JM, vanTuinen P, Ledbetter DH, Barker DF, Nakamura Y, White $\mathrm{R}$, Vogelstein B (1989) Chromosome 17 deletions and p53 gene mutations in colorectal carcinomas. Science (Washington DC) 244: 217-221

Bedenne L, Faivre J, Boutron MC, Piard F, Cauvin JM, Hillon P (1992) Adenoma-carcinoma sequence or 'de novo' carcinogenesis? A study of adenomatous remnants in a population-based series of large bowel cancers. Cancer 69: 883-888

Boland CR, Thibodeau SN, Hamilton SR, Sidransky D, Eshleman JR, Burt RW, Meltzer SJ, Rodriguez-Bigas MA, Fodde R, Ranzani GN, Srivastava S (1998) A National Cancer Institute Workshop on Microsatellite Instability for cancer detection and familial predisposition: development of international criteria for the determination of microsatellite instability in colorectal cancer. Cancer Res 58: $5248-5257$

Bos JL, Fearon ER, Hamilton SR, Verlaan-de Vries M, van Boom JH, van der Eb AJ, Vogelstein B (1987) Prevalence of ras gene mutations in human colorectal cancers. Nature (London) 327: 293-297

Bronner CE, Baker SM, Morrison PT, Warren G, Smith LG, Lescoe MK, Kane M, Earabino C, Lipford J, Lindblom A, Tannergard P, Bollag RJ, Godwin AR, Ward DC, Nordenskjold M, Fishel R, Kolodner R, Liskay RM (1994) Mutation in the DNA mismatch repair gene homologue hMLH1 is associated with hereditary non-polyposis colon cancer. Nature (London) 368: 258-261

Brose MS, Volpe P, Feldman M, Kumar M, Rishi I, Gerrero R, Einhorn E, Herlyn M, Minna J, Nicholson A, Roth JA, Albelda SM, Davies H, Cox C, Brignell G, Stephens P, Futreal PA, Wooster R, Stratton MR, Weber BL (2002) BRAF and KRAS mutations in human lung cancer and melanoma Cancer Res 62: 6997-7000

Chan TL, Zhao W, Cancer Genome Project, Leung SY, Yuen ST (2003) $B R A F$ and KRAS mutations in colorectal hyperplastic polyps and serrated adenomas. Cancer Res 63: 4878-4881

Cunningham JM, Christensen ER, Tester DJ, Kim CY, Roche PC, Burgart LJ, Thibodeau SN (1998) Hypermethylation of the hMLH1 promoter in colon cancer with microsatellite instability. Cancer Res 58: $3455-3460$

Davies H, Bignell GR, Cox C, Stephens P, Edkins S, Clegg S, Teague J, Woffendin H, Garnett MJ, Bottomley W, Davis N, Dicks E, Ewing R, Floyd Y, Gray K, Hall S, Hawes R, Hughes J, Kosmidou V, Menzies A, Mould C, Parker A, Stevens C, Watt S, Hooper S, Wilson R, Jayatilake H, Gusterson BA, Cooper C, Shipley J, Hargrave D, Katherine PJ, Maitland N, Chenevix-Trench G, Riggins GJ, Bigner DD, Palmieri G, Cossu A, Flanagan A, Nicholson A, Ho JWC, Leung SY, Yuen ST, Weber BL, Seigler HF, Darrow TL, Paterson H, Marais R, Marshall CJ, Wooster R, Stratton MR, Futreal PA (2002) Mutations of the BRAF gene in human cancer. Nature (London) 417: 949-954

Delaney AM, Printen JA, Chen H, Fauman EB, Dudley DT (2002) Identification of a novel mitogen-activated protein kinase kinase activation domain recognized by the inhibitor PD 184352. Mol Cell Bio 22: $7593-7602$

Domingo E, Espin E, Armengol M, Oliveira C, Pinto M, Duval A, Brennetot C, Seruca R, Hamelin R, Yamamoto H, Schwartz Jr S (2004) Active BRAF targets proximal colon tumors with mismatch repair deficiency and MLH1 inactivation. Genes Chromosomes Cancer 39: 138-142
English JM, Pearson G, Hockenberry T, Shivakumart L, White MA, Cobb MH (1999) Contribution of the ERK/MEK5 pathway to Ras/Raf signaling and growth control. J Biol Chem 274: 31588-31592

Forrester K, Almoguera C, Hank K, Grizzle WE, Perucho M (1987) Detection of high incidence of K-ras oncogenes during human colon tumorigenesis. Nature (London) 327: 298-303

Fransen K, Klintenas M, Osterstrom A, Dimberg J, Monstein HJ, Soderkvist P (2004) Mutation analysis of the BRAF, ARAF and RAF-1 genes in human colorectal adenocarcinomas. Carcinogenesis 25: 527-533

Fujimori T, Satonaka K, Yamashita-idei Y, Nagasako K, Maeda S (1994) Non-involvement of ras mutations in flat colorectal adenomas and carcinomas. Int $J$ Cancer 57: 51 -55

Herman JG, Umar A, Polyak K, Polyak K, Graff JR, Ahuja N, Issa JP, Markowitz S, Willson JKV, Hamilton SR, Kinzler KW, Kane MF, Kolodner RD, Vogelstein B, Kunkel TA, Baylin SB (1998) Incidence and functional consequences of hMLH1 promoter hypermethylation in colorectal carcinoma. Proc Natl Acad Sci USA 95: 6870-6875

Iishi H, Tatsuta M, Tsutsui S, Imanishi K, Otani T, Okuda S, Ishigro S, Taniguchi H (1992) Early depressed adenocarcinoma of the large intestine. Cancer 69: 2406-2416

Japanese Research Society for Cancer of the Colon and Rectum (1997) General Rules for Clinical and Pathological Studies on Cancer of the Colon, Rectum, and Anus, 1st English edn. Tokyo: Kanehara

Kambara T, Smims LA, Whitehall VLJ, Spring KJ, Wynter CVA, Walsh MD, Barker MA, Arnold S, McGivern A, Matsubara N, Tanaka N, Higuchi T, Young J, Jass JR, Leggett BA (2004) BRAF mutation is associated with DNA methylation in serrated polyps and cancer of the colorectum. Gut 53: $1137-1144$

Kaneko K, Kurahashi T, Makino R, Konishi K, Ito H, Katagiri A, Kumekawa Y, Hirayama $Y$, Yoneyama $K$, Kushima $M$, Kusano $M$, Tajiri $H$, Rembacken BJ, Mitamura K, Imawari M (2004) Pathological features and genetic alterations in colorectal carcinomas with characteristics of nonpolypoid growth. Br J Cancer 91: 312-318

Kinzler KW, Vogelstein B (1996) Lessons from hereditary colorectal cancer. Cell 87: $159-170$

Koinuma K, Shitoh K, Miyakura Y, Furukawa T, Yamashita Y, Ota J, Ohki R, Choi YL, Wada T, Konishi F, Nagai H, Mano H (2004) Mutations of $B R A F$ are associated with extensive $h M L H 1$ promoter methylation in sporadic colorectal carcinomas. Int J Cancer 108: 237-242

Kolch W (2000) Meaningful relationship: the regulation of the Ras/Raf/MEK/ERK pathway by protein interactions. Biochem $J$ 351: $289-305$

Konishi K, Fujii T, Boku N, Kato S, Koba I, Ohtsu A, Tajiri H, Ochiai A, Yoshida S (1999) Clinicopathological differences between colonic and rectal carcinomas: are they based on the same mechanism of carcinogenesis? Gut 45: 818-821

Konishi K, Kaneko K, Kurahashi T, Yamamoto T, Kushima M, Kanda A, Tajiri H, Mitamura K (2003) A comparison of magnifying and nonmagnifying colonoscopy for diagnosis of colorectal polyps: a prospective study. Gastrointest Endosc 57: 48-53

Konishi K, Yamochi T, Makino R, Kaneko K, Yamamoto T, Nozawa T, Katagiri A, Ito H, Nakayama K, Ota H, Mitamura K, Imawari M (2004) Molecular differences between sporadic serrated and conventional colorectal adenomas. Clin Cancer Res 10: $3082-3090$ 
Kudo S (1993) Endoscopic mucosal resection of flat and depressed types of early colorectal cancer. Endoscopy 25: 455-461

Makino R, Kaneko K, Kurahashi T, Matsumura T, Mitamura K (2000) Detection of mutation of the $p 53$ gene with high sensitivity by fluorescence-based PCR-SSCP analysis using low-pH buffer and an automated DNA sequencer in a large number of DNA samples. Mutat Res 452: $83-90$

Minamoto T, Sawaguchi K, Mai M, Yamashita N, Sugimura T, Esumi H (1994a) Infrequent K-ras activation in superficial-type (flat) colorectal adenomas and adenocarcinomas. Cancer Res 54: 2841 - 2844

Minamoto T, Sawaguchi K, Ohta T, Itoh T, Mai M (1994b) Superficial-type adenomas and adenocarcinomas of the colon and rectum: a comprative morphological study. Gastroenterology 106: 1436-1443

Morson BC (1968) Precancerous and early malignant lesions of the large intestine. Br J Surg 55: 725-731

Muto T, Bussey HJR, Morson BC (1975) The evolution of cancer of the colon and rectum. Cancer 36: $2251-2270$

Olschwang S, Slezak P, Roze M, Jaramillo E, Nakano H, Koizumi K, Rubio CA, Laurent-Puig P, Thomas G (1998) Somatically acquired genetic alterations in flat colorectal neoplasias. Int $J$ Cancer 77: $366-369$

Peyssonnaux C, Eychene A (2001) The Raf/MEK/ERK pathways: new concepts of activation. Biol Cell 93: 53-62

Powell SM, Zilz N, Beazer-Barclay Y, Bryan TM, Hamilton SR, Thibodeau SN, Vogelstein B, Kinzler KW (1992) APC mutations occur early during colorectal tumorigenesis. Nature (London) 359: 235-237

Rajagopalan H, Bardelli A, Lengauer C, Kinzler KW, Vogelstein B, Velculescu VE (2002) RAF/RAS oncogenes and mismatch-repair status. Nature (London) 418: 934

Rembacken BJ, Fujii T, Cairns A, Dixon MF, Yoshida S, Chalmers DM, Axon AT (2000) Flat and depressed colonic neoplasms: a prospective study of 1000 colonoscpies in the UK. 355: 1211-1214

Richter H, Slezak P, Walch A, Werner M, Braselmann H, Jaramiro E, Ost A, Hirata I, Takahama K, Zitzelsberger H (2003) Distinct chromosomal imbalances in nonpolypoid and polypoid colorectal adenomas indicate different genetic pathways in the development of colorectal neoplasms. Am J Pathol 163: 287-294
Saitoh Y, Waxman I, West AB, Popnikolov NK, Gatalica Z, Watari J, Obara T, Kohgo Y Pasricha PJ (2001) Prevalence and distinctive biologic features of flat colorectal adenomas in a North American population. Gastroenterology 120: 1657-1665

Shimoda T, Ikegami M, Fujisaki J, Matsui T, Aizawa S, Ishikawa E (1989) Early colorectal carcinoma with special reference to its development de novo. Cancer 64: $1138-1146$

van Wyk R, Slezak P, Hayes VM, Buys CH, Kotze MJ, de Jong G, Rubio C, Dolk A, Jaramillo E, Koizumi K, Grobbelaar JJ (2000) Somatic mutations of the APC, KRAS, and TP53 genes in nonpolypoid colorectal adenomas. Genes Chromosomes Cancer 27: 202-208

Vogelstein B, Fearon ER, Hamilton SR, Kern SE, Preisinger AC, Leppert M, Nakamura Y, White R, Smits AM, Bos JL (1988) Genetic alterations during colorectal-tumor development. $N$ Engl J Med 319: 525-532

Vojtek AB, Der CJ (1998) Increasing complexity of the Ras signaling pathway. J Biol Chem 273: 19925-19928

Wang L, Cunningham JM, Winters JL, Guenther JC, French AJ, Boardman LA, Burgart LJ, McDonnell SK, Schaid DJ, Thibodeau SN (2003) BRAF mutations in colon cancer are not likely attributable to defective DNA mismatch repair. Cancer Res 63: 5209-5212

Yamagata S, Muto T, Uchida Y, Masaki T, Sawada T, Tsuno N, Hirooka T (1994) Lower incidence of K-ras codon 12 mutation in flat colorectal adenomas than in polypoid adenomas. Jap J Cancer Res 85: 147 - 151

Yamamoto T, Konishi K, Yamochi T, Makino R, Kaneko K, Shimamura T, Ota H, Mitamura K (2003) No major tumorigenic role for $\beta$-catenin in serrated as opposed to conventional colorectal adenomas. Br J Cancer 89: $152-157$

Yashiro M, Carethers JM, Laghi L, Saito K, Slezak P, Jaramillo E, Rubio C, Koizumi K, Hirakawa K, Boland R (2001) Genetic pathways in the evolution of morphologically distinct colorectal neoplasms. Cancer Res 61: $2676-2683$

Yuen ST, Davies H, Chan TL, Ho JW, Bignell GR, Cox C, Stephens P, Edkins S, Tsui WW, Chan AS, Futreal A, Stratton MR, Wooster R, Leung SY (2003) Similarity of the phenotypic patterns associated with BRAF and KARS mutations in colorectal neoplasia. Cancer Res 62: 6451-6455

Zimmermann S, Moelling K (1999) Phosphorylation and regulation of Raf by Akt (protein kinase B). Science (Washington DC) 289: 1741 - 1744 